\title{
SECONDARY HYPOTHYROIDISM AND THE TARSAL TUNNEL SYNDROME
}

\author{
Authors: Blertina Dyrmishi 1; Taulant Olldashi ${ }^{2}$; \\ 1- Endocrinologist, Hygeia Hospital Tirana-Albania; 2- Orthopedist, Hygeia Hospital Tirana-Albania
}

\section{BACKGROUND}

- Tarsal tunnel syndrome is classified as a focal compressive neuropathy of the posterior tibial nerve or one of its associated branches individually or collectively.

- The tunnel courses deep to fascia, the flexor retinaculum and within the abductor hallucis muscle of the foot/ankle.

- The condition is rare and regularly under-diagnosed leading to a range of symptoms affecting the plantar margins of the foot.

- There are many intervention strategies for treating tarsal tunnel syndrome with limited robust evidence to guide the clinical management of this condition.

-In many cases, the neurologic manifestations occur in conjunction with the systemic features of the disease and may be noted only incidentally. However, symptoms and signs of neurologic dysfunction may be the presenting feature in some patients and can contribute significant disability. Most of these complications are partially or fully responsive to thyroid replacement.

\section{RADIOLOGY DATA}

Thyroid scintigraphy with Tc99; left hand X-ray (bone age) and thyroid ultrasound
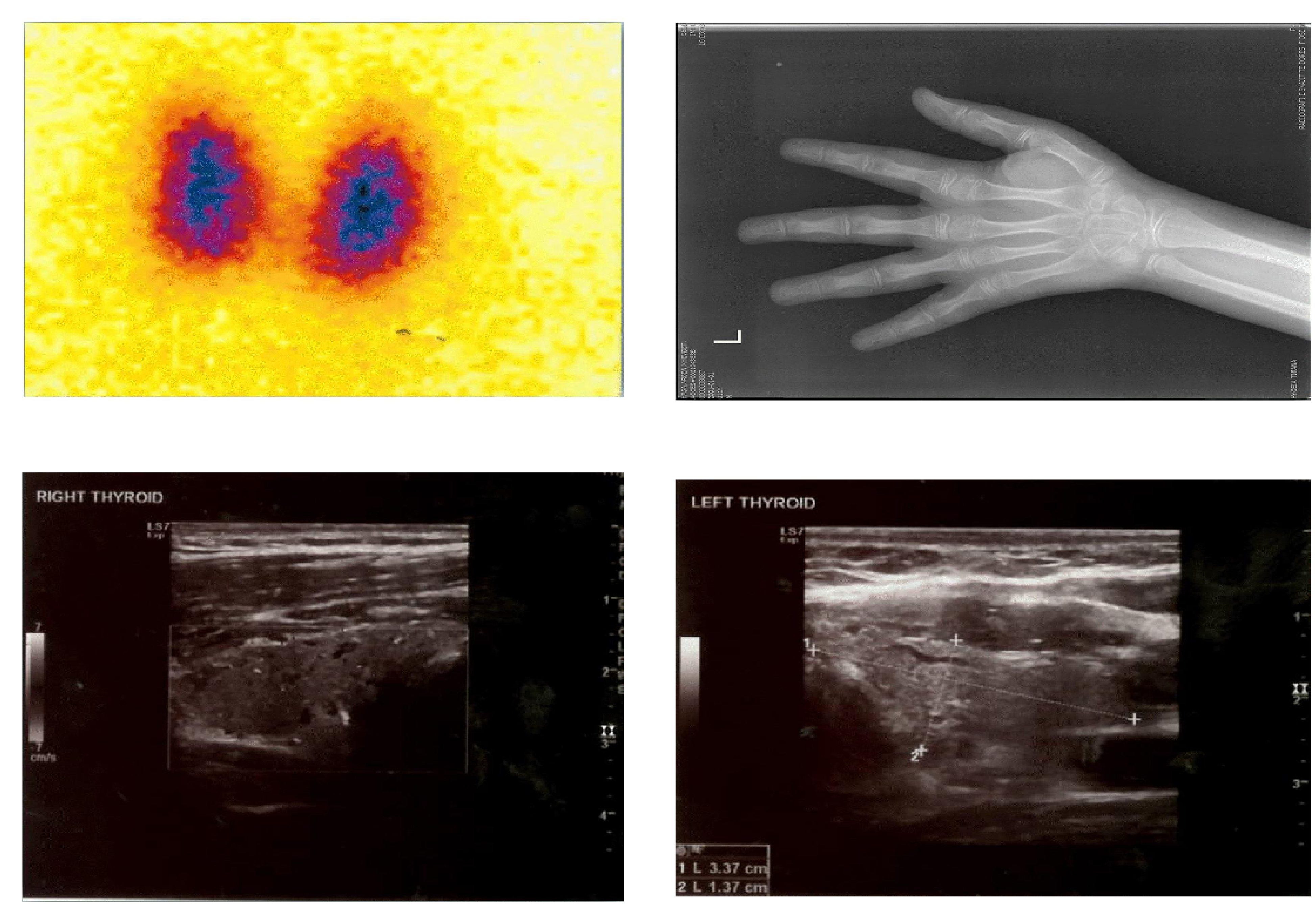

1. Prolonged untreated hypothyroidism may have neurological complication including tarsal tunnel syndrome

2. There are few cases reports study ofpatient with tunnel tarsal syndrome as a cause of hypothyroidism.

3. We need to do again ore complete electrophysiological studies to excluded more generalized peripheral neuropathy.

\section{THE CASE}

- We referred one case with secondary hypothyroidism and tarsal tunnel syndrome.

-The boy 11 and 6/12 years old was presents in our clinic with:
-Fatigue
-Obesity
-Difficulty during walking
-Low performance in school
-Hyposthenia
-Mental impairment
-Anthropometric data:
Weight $48 \mathrm{~kg}+3.8 \mathrm{SD}$
Height $153 \mathrm{~cm}+2 \mathrm{SD}$

-The patient has bilateral symptoms of the tarsal tunnel syndrome and his foot symptom was aggravated by walking

\section{RESULTS}

The hormonal values were:

$\begin{array}{lcl}\text { TSH } & 2.3 \mathrm{mUl} / \mathrm{ml} & (0.35-4.04) \\ \text { FT4 } & 0.54 \mathrm{ng} / \mathrm{dl} & (0.93-1.7) \\ \text { FT3 } & 1.97 \mathrm{ng} / \mathrm{dl} & (2.3-4.2) \\ \text { Ab anti TPO } & 12.2 \mathrm{Ul} / \mathrm{mL} & (<70) \\ \text { Ab anti Tg } & 24 U \mathrm{UL} / \mathrm{mL} & (<70)\end{array}$

Thyroid ultrasound : Isoecogenic structure in both lobes of thyroid.

MRI of head: Normal

The electro diagnostic study : Show evidence of bilateral tarsal tunnel syndrome (examination show chronic diffuse suffering of neurologic type of central origin with normal distal motor latencies bilaterally). Compression of tibial nerve in the tarsal tunnel.

The patient started the treatment with levothyroxine and after 6 months of treatment the FT3 and FT4 were in the normal range, but the tarsal syndrome is not improved and he was underwent surgical treatment for tarsal tunnel release

\section{REFERENCES}

-Schwartz, M. S., C. G. Mackworth-Young, and R. O. McKeran. "The tarsal tunnel syndrome in hypothyroidism." Journal of Neurology, Neurosurgery \& Psychiatry 46.5 (1983): 440-442.

-Bailie, David S., and Armen S. Kelikian. "Tarsal Tunnel Syndrome:

Diagnosis, Surgical Technique, and Functional Outcome*." Foot \& ankle international 19.2 (1998): 65-72.

-Mondelli, M., F. Giannini, and F. Reale. "Clinical and electrophysiological findings and follow-up in tarsal tunnel syndrome." Electroencephalography and Clinical Neurophysiology/Electromyography and Motor Control 109.5 (1998): 418-425 